\title{
Differential Association Theory Reconsidered: An Extension and Its Empirical Test
}

\author{
Gerben J. N. Bruinsma ${ }^{1}$
}

In 1974 the German methodologist Karl-Dieter Opp expounded and expanded Sutherland's differential association theory. In this article an empirical test of this version of the theory is presented based on data for 1196 boys and girls in the age range 12 to 17 years. Furthermore, some new and additional theoretical specifications about the social influence of others on the individual, all in accordance with the original ideas of Sutherland, are proposed and empirically tested. The differential association theory according to the version of K.-D. Opp is fairly well corroborated by the data. Only three of the postulated relationships are rejected. The theory explains $51 \%$ of the variance of criminal behavior, even considering that no "criminal" population is used for the test and only minor offenses are measured. The test also shows that the impact of the frequency of contacts with deviant behavior patterns on the development of positive definitions and on the frequency of communication about relevant techniques is substantial and cannot be ignored by criminologists. Furthermore, special analyses show that several propositions favor the theory. It is the deviancy of others that has the most substantial impact: the more youngsters have contact with their friends, the stronger the impact of the deviancy of their friends on the development of positive definitions or on the frequency of communication about techniques. The tests also show that the more youngsters identify themselves with others, the stronger will be the impact of the deviancy of the others on their norms. These results support the modification of the DA theory according to Opp and falsify some propositions of social control theory.

KEY WORDS: differential association theory; criminological theory; juvenile delinquency.

\section{INTRODUCTION}

During the past 15 years, when social control theories have been rampant in criminology, the differential association theory has been neglected, rejected, or put away as a dusty museum piece in criminology textbooks.

\footnotetext{
'Department of Sociology, Faculty of Public Administration and Public Policy, University of
} Twente, Enschede, The Netherlands. 
However, it cannot be ignored that differential association theory has contributed much to the field of criminology. This relatively old theory, developed by the American sociologist, Edwin Hardin Sutherland (1883-1950) states in a nutshell that crime is a product of a social process in which interactions with deviant behavior patterns play an important role. Over a period of 20 years Sutherland has published different versions of his theory with which he tried to give a universal explanation of crime. His theory has influenced criminology for a long time (Laub and Sampson, 1991; Matsueda, 1988). Many criminologists have criticized, rejected, reformulated, and modified Sutherland's propositions (among others, Glaser, 1969, 1978; Matza and Sykes, 1957; Cloward, 1959; de Fleur and Quinney, 1966; Burgess and Akers, 1966). But empirically the theory has a bad reputation among criminologists. Many researchers report insurmountable problems in empirical testing of Sutherland's theory and little progress has been demonstrated in 30 years of research (Springer, 1973; Opp, 1974; Bruinsma, 1985; Matsueda, 1988).

The modification of the German methodologist K.-D. Opp (1974) shows much progress compared with its predecessors. In accordance with his critical rationalist point of view, he improves and extends the theory of differential association (DA) in such a way that not only an informative theory is developed but also an empirical test has come within reach. In this article an empirical test of this version of the differential association theory is presented on the basis of data of 1196 boys and girls in the age range 12 to 17 years. Furthermore, some new and additional theoretical specifications about the social influence of others on the individual, all in accordance with the original ideas of Sutherland, are proposed and empirically tested as well.

\section{THE DIFFERENTIAL ASSOCIATION THEORY}

The differential association theory has a remarkable history as a consequence of the fact that Sutherland has published four different versions of his explanation of crime in successive editions of his textbook Principles of Criminology over a period of 20 years. [For more information about the development of the theory see Bruinsma (1985), Sutherland (1956), and Gaylord and Galliher (1988).]

In the first edition of his textbook, in 1924, Sutherland is, as he acknowledged later (1956), a follower of the multiple-factor approach. Despite that point of view a number of important starting points of his DA theory can be found:

(a) the search for a universal explanation of crime;

(b) attention for the interaction of the individual and his/her social environment; 
(c) interest in cultural- and macrosocial conflicts and their consequences for the individual; and

(d) the idea that crime, like all other behavior, is learned and is not the result of heritable defects.

In the second edition, in 1934, Sutherland's own vision has come in sight. Consistent with his thesis about crime as learned behavior, Sutherland added, "Failure to follow a prescribed pattern of behavior is due to the inconsistency and lack of harmony in the influences which direct the individual" (Sutherland, 1934, p. 52). More strongly than ever before, he joined the so-called "Chicago school" of sociology, in which macrosocial (cultural) conflicts are assumed to be central for the explanation of human behavior.

In 1939 Sutherland opened his third, and largely revised, edition of Principles of Criminology with a chapter in which he presents his own theory in the form of seven propositions. With these propositions he tried to connect three levels of explanations: the macro level (that of culture conflicts), the meso level (that of social disorganization), and the individual level (that of having contacts with criminals, that is, in 1939, differential association). The crux of this version is that systematic criminal behavior is determined by the process of association with criminals just as systematic law-conforming behavior is developed in a process of association with law-conforming people. Cultural conflict is the underlying cause of differential association and social disorganization is the basic cause. In this version Sutherland ascribed a limited sense to associations with criminal behavior patterns, namely, only associations with a criminal subculture. Belonging to such a subculture implies that the ratio of contacts turns in favor to one side.

Eight years later the definitive version of his theory was published. A remarkable difference from its predecessors is the elimination of all propositions which are about processes of a higher aggregational level. More than ever, Sutherland emphasized the learning process of the individual. The content of the concept of differential association radically changed: "A person becomes delinquent because of an excess of definitions favorable to violation of law over definitions unfavorable to violation of law" (Sutherland, 1947, p. 7). In 1947 his propositions are stated as follows.

(1) Criminal behavior is learned;

(2) criminal behavior is learned in interaction with other persons in a process of communication;

(3) the principal part of the learning of criminal behavior occurs within intimate personal groups;

(4) when criminal behavior is learned, the learning includes;

(a) techniques of committing the crime, which are sometimes very complicated, sometimes very simple;

(b) the specific direction of motives, drives, rationalizations and attitudes;

(5) the specific direction of motives and drives is learned from definitions of the legal codes as favorable or unfavorable; 
(6) a person becomes delinquent because of an excess of definitions favorable to violation over definitions unfavorable to violation of law;

(7) differential associations may vary in frequency, duration, priority, and intensity;

(8) the process of learning criminal behavior by association with criminal and anti-criminal patterns involves all of the mechanisms that are involved in any other learning; while criminal behavior is an expression of general needs and values, it is not explained by those general needs and values since noncriminal behavior is an expression of the same needs and values. (Sutherland, 1947, pp. 6-7)

\section{THEORETICAL AND EMPIRICAL CRITICISMS}

An inventory of 40 years of the theoretical and empirical research history of the DA theory shows that theoretically many researchers draw their inspiration from Sutherland's theory. A lot of them tried to reformulate the DA theory. Some of them are well-known. Glaser formulated his differential identification theory in 1966 and his differential anticipation theory in 1978, Cloward (1959) based his differential opportunity theory on Sutherland's theory (and on the anomie theory of Merton), de Fleur and Quinney (1966) reformulated the theory in terms of formal calculus, and Burgess and Akers (1966) modified Sutherland's theory in terms of behavioristic explanations (Law of Operant Behavior).

Despite all these efforts to improve the theory of Sutherland, it remains vague, too abstract, confusing, and in essence untestable. So the theory remained subject to heated debates since the last version, although most critiques by criminologists were published after Sutherland's death. Cressey (1969) draws an inventory containing the most frequently quoted theoretical critical remarks about the differential association theory.

The former conclusion about the DA theory on the theoretical level is also supported when the empirical research is considered (Bruinsma, 1985, pp. 49-63; Matsueda, 1988).

(1) During a period of 40 years the DA theory has never been empirically tested completely. All tests contained some fragments of propositions. The majority of the empirical research is concentrated on the seventh proposition of Sutherland's theory.

(2) All researchers report troubles with the measurement of the concepts of the theory.

(3) There is no agreement on the meaning of the most central concept of Sutherland's theory, "the excess of positive definitions of deviant behavior." Does the concept refer to the person whose behavior has to be explained, or does the concept refer to the context of the criminal offender? 
(4) The other central propositions of the DA theory about the interaction processes and communication processes are, to my own knowledge, never tested in any research.

(5) A lot of fragments of some propositions are tested wrongly. Not only are the concepts measured incorrectly, but in many cases additional variables are included in the theory (social class, for instance) that have nothing (or only in an indirect way) to do with the theory of Sutherland.

(6) In the United States researchers have interpreted and tested differential association only in terms of delinquent friends who are supposed to have a "bad" influence on other youngsters, perpetuating the misunderstanding that DA theory is the same as "bad companions cause crime."

So most empirical research is concentrated on delinquent friends, and in those cases when parents are involved in the tests, they are supposed to be law-conforming. However, the latter supposition has, to my knowledge, never been tested properly.

\section{OPP'S VERSION OF THE DIFFERENTIAL ASSOCIATION THEORY}

In 1974 the German methodologist Karl-Dieter Opp published his book Abweichendes Verhalien und Gesellschaftsstruktur, expanding many wellknown criminological theories in accordance with his critical rationalist point of view. One of the theories Opp explicated and modified was Sutherland's. ${ }^{2}$

Opp started his reformulation with the central sixth proposition of the DA theory, which provides relatively the most precise information about the conditions of criminal behavior. These positive definitions, however, are learned in a process of interaction with deviant behavior patterns. Furthermore, Opp accentuated another process in the DA theory. He stated that techniques relevant for committing a crime are learned in a process of communication. Opp kept only four variables of the original version: an excess of positive definitions of deviant behavior and the priority, frequency, and intensity (identification) of contacts. These concepts were (re)defined and thereafter seen as of only indirect importance for the explanation of crime.

Opp inserted five new variables (two of which are brought out by Sutherland himself in some scattered articles): (a) the frequency of communications about techniques, (b) the effectiveness of techniques, (c) the intensity

${ }^{2}$ Due to a shortage of space the discussion of Opp's modification is restricted here to the main results [for more information, see Opp (1974) and Bruinsma (1985)]. 
of norms regulating deviance, (d) the opportunities for committing crimes, and (e) the intensity of needs. With the help of the last four variables, Opp tried to give an explanation of the frequency of criminal acts of an individual. Moreover, Opp introduced a new relation in the theory (see proposition $\mathrm{E}$ below), which makes the theory nonrecursive. On account of his explication and modification, Opp presented the following five "if ..., then ..." statements:

A The more frequently an individual comes in contact with deviant behavior patterns (I),

the stronger will be the excess of positive definitions of deviant behavior (III), and the more frequent will be the communications about techniques which are relevant to the performance of deviant behavior (V).

B The higher the priority of deviant contacts (II),

the stronger the excess of positive definitions of deviant behavior (III),

and the higher the degree of identification with the source of deviant contacts (IV),

the more intense will be the individual's norms regulating deviance (VII).

C The more frequently an individual communicates about techniques which are relevant to the performance of deviant behavior $(V)$,

the more effective will be his/her techniques in performing deviant behavior (VIII).

D The more intense the needs of the individual (VI),

the more intense his/hers norms regulating deviance (VII),

the more effective his/her techniques in performing deviant behavior (VIII), and the greater the opportunities which occur for deviant behavior (IX), the more frequently will he/she be engaged in deviant activities for which the deviant norms are relatively intense and for which the techniques are relatively effective and the opportunities relatively great (X).

E The more frequently an individual behaves deviantly $(\mathrm{X})$, the more frequent will be his/her contacts with deviant behavior patterns (I).

Before presenting the empirical test of Opp's version of the theory some general remarks have to be made.

First, although Opp's reformulation of Sutherland's theory means another step toward empirical testing, such a test is still difficult to execute. The main reason is that most theoretical concepts are very abstract and therefore it is difficult to find concrete empirical indicators. And above all, most of these concepts have never been measured in other studies. This means that there is no tradition on which the research could rely. Therefore a pilot study was executed in order to test the new developed research instruments (Bruinsma and Zwanenburg, 1980). This instrumental study based on data of 244 youngsters gave rise to some fundamental changes in the original research instruments. 
Second, a comment has to be made about the first proposition. One of the criteria of an informative theory is that its structure must be clear (Opp, 1974). This implies that it is known to which objects what properties are ascribed and what relationship(s) these properties have to one another. The objects of Opp's theory are people. In his proposition A, Opp states in the explanation, "the stronger will be the excess of positive definitions of deviant behavior." However, no objects are mentioned herein. This relatively small issue has important consequences for the content of the theory and, consequently, for its empirical test. What is it all about? Is it the excess of definitions of individuals whose deviant behavior has to be explained or is it the excess of presented position definitions? This indistinctness in the modification of Opp implies that a choice has to be made between both interpretations. The first argues the fact that when these definitions are attributed to the surroundings of an an individual, it is assumed that people are only passive recipients of impulses, without any capacity of assimilation. Therefore preference is given to the interpretation that the positive definitions favorable to deviant behavior belong to the individual whose behavior must be explained, although it will be realized that the other interpretation may not be as valid as well.

Third, the last proposition cannot be tested, for three reasons: (a) It is not plausible that only the frequency of deviant behavior is the cause of the kind of contacts one has. An alternative explanation may be obtained from the differential group-organization theory of Sutherland (1947). In other words, for theoretical reasons, testing only a bivariate relaticnship will not be very interesting. (b) It is not plausible that the feedback mechanism, adopted from Glueck (1956), is a direct one as Opp stated. This means that some kind of (unknown?) intermediating process is active between the two phenomena. (c) As we will see later, the data are based on a one-moment survey. Strictly speaking, a test of this kind of feedback mechanism requires a panel survey.

Fourth, in Opp's propositions two complex theoretical constructs play an important role: the frequency of contacts with deviant behavior patterns and the degree of identification with the source of deviant contacts. These concepts each consist of two elements: the frequency of contacts or the degree of identification and the deviancy of those contacts or sources. In order to test Opp's theory a solution has to be found for the problem of these so-called "multiplicative terms," because the use of the separate elements for the test will not be correct. The solution is found by multiplying the scales of the frequency of contacts and degree of identification by the dichotomous deviancy scale $(+1$ if they are deviant and -1 when these contacts are conforming). So in this way a continuum was constructed, varying from "frequent contacts with deviant behavior patterns" at one end to "frequent 
contacts with conforming behavior patterns" at the other end. With the aid of this construct, a test of Opp's theory will be more valid.

Furthermore, the measurement of contacts or identification is limited to only two contact categories, namely, the parents and the friends, in order to be able to refer to the literature as much as possible. It is realized that young people may have more contacts with others. ${ }^{3}$

\section{THE MEASUREMENT OF OPP'S THEORY}

Budgetary circumstances and limited staff force a clustered approximation of the population. As in the preceding extensive pilot study (Bruinsma and Zwanenburg, 1980), youngsters 12 to 17 years old were chosen because they are in the middle of their socialization process, a period in which the social process of criminal behavior can be best studied.

One thousand ninety-six boys and girls from a cross section of five secondary schools were questioned with the help of self-ratings and selfreports. The cluster sample, however, is not representative for the Dutch youth, but enough so to test the degree of truth of the theory. The teachers were not allowed in the classrooms during the research and the pupils were guaranteed anonymity.

In this study simple unidimensional indices were constructed with the help of item and reliability analyses combined with principal-factor analyses in order to check for dimensionality of the data (Carmines and Zeller, 1979).

Opp's theory tries to give an explanation for the frequency of deviant behavior. Opp defines deviant behavior as "Wenn eine Person durch eine Verhaltungsweise die von ihr perzipierte Erwartung mindestens einer anderen Person oder Institution verletzt" (Opp, 1974, p. 43). This means that no proposition is constructed about the seriousness of the criminal act. The frequency of criminal behavior is measured by responses to 15 questions about property crimes and behavior relatively prevalent among young people. Response choices of "never," "once or twice," or "more than twice" indicated whether respondents had committed any of the criminal acts in the previous year. Three items were not used in the Likert scale (with a reliability coefficient Cronbach's $\alpha$ of 0.78 ) (see also Bruinsma, 1989).

The frequency of contacts was measured by the time-passing of the youngsters after school (including evenings and weekends). They were asked how frequently and for how long they have contacts with their parents and

\footnotetext{
${ }^{3}$ It must be clear that the role of the siblings is seen as important as well, but the pilot study made clear that there are a great number of unsolvable practical problems when all the theoretical concepts must also be measured for the siblings.
} 
friends in a defined period of time. Seven of nine items represent one factor ( $40.2 \%$ explained variance). With these items two scales were constructed: one for the frequency of contacts with their parents and one for the contacts with their friends.

The sample was also asked about the deviancy of their parents and friends. For the parents deviancy scale questions about fighting behavior of and maltreatment by the father and shoplifting, bicycle theft, and lying by both parents were asked. The deviancy scale for the friends consists of statements about theft, smoking hashish, truancy, police contacts, and driving a moped before the age of 16. Measurement of the parents' deviancy has not been very successful. The items represent two factors that explain $43.6 \%$ of the variance. Only three items of the first factor could be used for the scale (with a low $\alpha$ of 0.34 ). The $\alpha$ coefficient for the friends' scale is much higher $(0.70)$. The items represent one factor $(45.9 \%)$. For the test of Opp's theory the two scales were made dichotomous (see below).

The priority of contacts was established by a single question about the period of knowing the friends one has at the moment of the survey.

The positive definitions of deviant behavior were measured by 15 selected items with which the youngsters were able to give opinions about deviancy in general. Some of the statements are neutralization techniques (Matza and Sykes, 1957), while others are about the use of deviant behavior in social life and moral judgments about deviancy. The scale consists of 12 items representing the first factor $(25.7 \%)$ with an $\alpha$ of 0.76 .

The identification with the source of deviant contacts was operationalized by the following indicators of the relationship between youngsters and their parents or friends: imitation, protection, opinion leader, company, support, opinion similarity, and intimacy. It is possible for youngsters to identify themselves to both parents and friends. The scale for identification with parents consists of six items (representing the first factor with an explained variance of $41.0 \%$ ) and has an $\alpha$ of 0.70 . The scale for identification with friends consists of seven items (one factor with $39.0 \%$ explained variance) and has a reliability of 0.78 . Subsequently the two scales are multiplied by +1 or -1 as stated above.

For the measurement of the concept the frequency of communication about relevant techniques, some connection was made to the measurement of the dependent variable of the theory. Questions were asked only about the communication of techniques necessary for the commitment of property crimes such as shoplifting, bicycle theft, using public transportation without paying, breaking into the coin box of a machine, etc. The questions did not specify with whom one was communicating. Furthermore, some questions were about the communication of techniques with their parents and their 
friends, and two questions were about the inquisitive aspect of communication by the respondent. The final scale consists of the dichotomous scores of the 10 items $(\alpha=0.75)$ representing one factor $(31.3 \%)$.

The intensity of needs was specified as the degree to which youngsters are relatively deprived of material goods. The intensity was measured by questions about the frequency with which they want to possess such goods and the efforts they are willing to expend to get them. After factor analyses five items remain, explaining $32.5 \%$ of the variance. This scale is weak, with a low $a$ coefficient of 0.47 .

The intensity of norms regulating deviancy was measured by asking the young people in what concrete situations they will permit or exclude themselves to commit a property crime. The four remaining items represent one factor with $43.3 \%$ explained variance and an $\alpha$ of 0.55 .

The effectiveness of techniques can be described as the skills necessary to execute a certain criminal act. The youngsters were asked if they think they possess the skills to commit shoplifting, bicycle theft, using public transportation without paying, breaking the coin box of a machine, or a burglary. Factor analyses show that the items represent one factor $(49.4 \%)$ and the scale has an $\alpha$ of 0.74 .

The opportunities are described by Opp as the degree to which objects or persons are available for executing deviant behavior. Information is gathered about the perception of situations where criminal acts are relatively easy to commit, carrying tools with them, and possible help from friends when committing a crime (imaginary or in real situations). The analyses indicate two items to be unsuitable and the remaining items represent one factor $(45.9 \%)$. The scale has a reliability of 0.60 .

\section{THE RESULTS OF THE TEST}

Figure 1 presents the causal diagram containing the results of path analysis. ${ }^{4}$ The strength of the path coefficients ${ }^{5}$ and their signs indicate that the first proposition is corroborated by the data. There are positive causal effects from the frequency of contacts with deviant parents and deviant friends on the formation of positive definitions of deviant behavior and on the frequency of communication about relevant techniques. The influence

\footnotetext{
${ }^{4}$ For information about the Pearson correlations, see Table AI (Appendix). Because of the way in which the "multiplicative terms" were constructed, a stepwise test of the theory using path analysis was preferred to Lisrel analysis. In this way multicollinearity was avoided in the assessment of the parameters. A secondary analysis with the aid of Lisrel demonstrates that this decision was right (Fiselier and Verschuren, 1988).

${ }^{5}$ Because of the large sample and the fact that the sample is not random, the criterion of substantiality of the path coefficients $>0.10$ was used instead of statistical testing.
} 


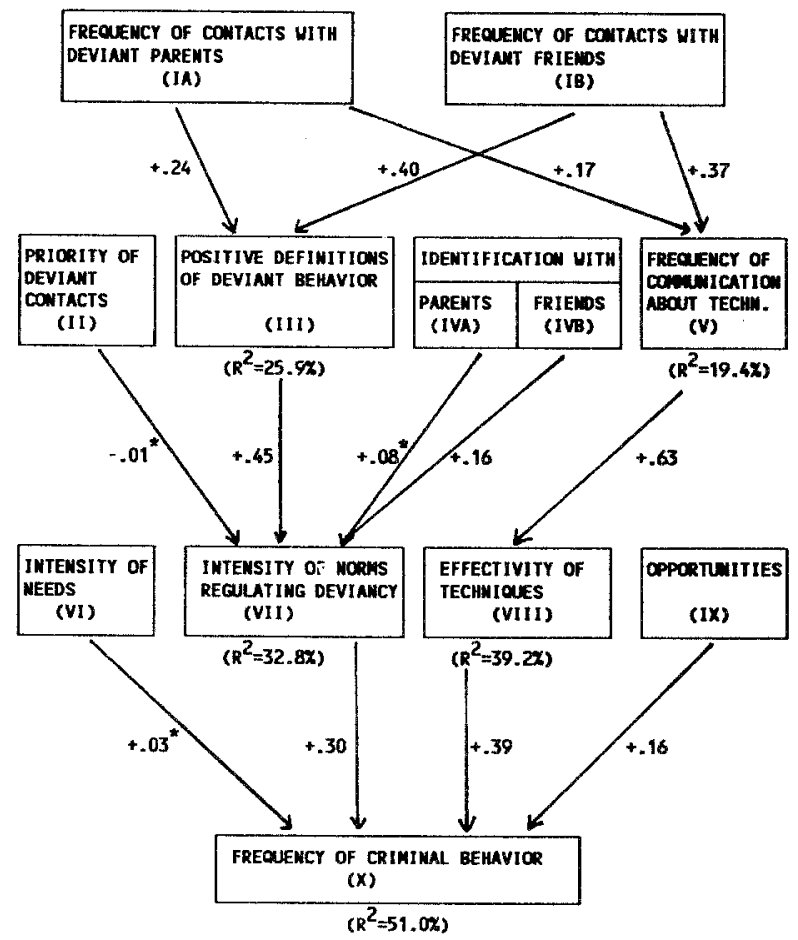

Fig. 1. General test of the differential association theory, K.-D. Opp's Version $(N=960)$. (*) Not substantial $(<0.10)$. Source: Bruinsma $(1985$, p. 152).

from the parents is, however, less than the influence of the friends. The two variables explain $25.9 \%$ of the positive definitions and $19.4 \%$ of the frequency of communication. For both dependent variables, the frequency of contacts with deviant friends exercises the strongest influence. This is especially the case for the frequency of communication about techniques, where the influence of contacts with friends is twice as great as that of contacts with parents. I will return to this subject later.

The second proposition is partly falsified by the empirical facts. Two postulated relationships do not conform to expectations. The priority of deviant contacts and the degree of identification with deviant parents do not have a substantial causal effect on the intensity of norms regulating deviancy. The fact that priority does not have any effect is consistent with empirical criminological research. The correlation matrix in Table AI (Appendix) shows that priority has no empirical relationship with any other variable of the theory.

The test demonstrates once more that friends exert a stronger influence than parents. The difference of impact shows that in reality the processes of 
attachment are much more complex than assumed in theory (Hirschi, 1969). This subject is discussed later. The degree of identification with deviant friends has a positive causal effect on the norms. The strongest effect, however, is from the positive definitions $(+0.45)$.

The third proposition is corroborated in the empirical confrontation. It means that youngsters learn a lot from communication with others about relevant techniques. There is only one question to be mentioned here which cannot be answered by this research. The reverse causal process, namely, that people who believe their own techniques in performing criminal acts effectively may also communicate more often with other people about these techniques may be effective as well.

The fourth proposition is corroborated partly. The intensity of needs, measured as relative deprivation, has no substantial effect on the frequency of criminal acts. The other three variables explain $51 \%$ of the variance, which is relatively high according to the standards of social research. The effectiveness of the techniques is the best explanation of the variable frequency of crime $(+0.39)$, followed in decreasing order by the intensity of norms regulating deviancy $(+0.30)$ and the opportunities to commit crimes $(+0.16)$.

\section{EXTENSION 1: A SPECIFICATION OF SOCIAL INFLUENCES}

The findings so far indicate that Opp's version of the DA theory is, for the most part, supported by the data. However, until now the mechanism of some social influences on the development of criminal behavior of youngsters has been underexposed. From the test of the first proposition, it can be concluded that friends are much more important for the development of crime by youngsters than parents are. However, the test shows that parents do exercise some deviant influence on their children. This empirical finding is very basic because until recently criminologists assumed that parents socialize their children in a conforming way, independent of their own (perhaps hidden) deviancy.

To explore the impact of the significant others, the elements of the complex concepts were separated again. This leads to four new variables: (a) the frequency of contacts with parents, (b) the frequency of contacts with friends, (c) the deviancy of the parents, and (d) the deviancy of the friends. Table I presents the analyses of the impact of social influences on the development of positive definitions of deviant behavior and on the frequency of communication about relevant techniques. The data indicate that the most important factor for the explanation of the positive definitions of deviant behavior is the deviancy of friends, followed by the deviance of the parents and the frequency of contacts with friends. The lowest and 
Table I. Specification of Social Influences on the Development of Positive Definitions and on the Frequency of Communication About Techniques $(N=1027)^{a}$

\begin{tabular}{lcrr}
\hline \multicolumn{1}{c}{ Kind of social influences } & Pearson & Path & $R^{2}$ \\
\hline \multicolumn{4}{c}{ Positive definitions of deviant behavior } \\
Deviancy of friends & 0.55 & 0.46 & $30.5 \%$ \\
Frequency of contacts with friends & 0.35 & 0.11 & $3.8 \%$ \\
Deviancy of parents & 0.25 & 0.13 & $1.6 \%$ \\
Frequency of contacts with parents & -0.37 & -0.11 & $0.3 \%$
\end{tabular}

Frequency of communication about techniques

\begin{tabular}{lrrc} 
Deviancy of friends & 0.51 & 0.43 & $26.0 \%$ \\
Frequency of contacts with friends & 0.37 & 0.13 & $4.9 \%$ \\
Deviancy of parents & 0.15 & 0.03 & - \\
Frequency of contacts with parents & -0.38 & -0.13 & $0.4 \%$ \\
\hline
\end{tabular}

${ }^{a}$ Source: Bruinsma (1985, p. 157).

negative path coefficient is found for the frequency of contacts with the parents.

An important conclusion is that the deviancy of others is the best explanation for the development of positive definitions. This result conforms to the ideas of Sutherland himself. The results also suggest that criminologists should no longer assume that law-abiding parents automatically help deter criminal behavior in their children. However, when we keep in mind the fact that (1) by the skew frequency distribution of this variable no strong empirical relationships are possible, and (2) only minor deviant forms of behavior are measured, this impact of the deviancy of the parents cannot be ignored theoretically.

For the explanation of the frequency of communication of relevant techniques, the deviancy of parents plays an insubstantial role. The best explaining factors are the deviancy of friends and, to a lesser degree, the frequency of contacts with friends. The more often adolescents have contacts with their parents, the less they will communicate about relevant techniques. This means that relevant techniques for committing crimes are learned from the friends and not from the parents. Parents are thus more important for learning positive definitions than for communication about techniques.

\section{EXTENSION 2: A FURTHER SPECIFICATION OF SOCIAL INFLUENCES}

The deviancy of friends is thus a very important social influence for the development of positive definitions. However, with the analyses so far we 
cannot answer the following theoretically important question: Is the degree of impact of the deviancy of others on the development of positive definitions of deviant behavior independent of the number of times one meets with the others? This question is obviously very fundamental for differential association theory, and a more detailed analysis is required to answer it. For the analyses the boys and girls were divided into five groups depending on their frequency scores on the variable contacts with friends. The five groups varied from having a low frequency of contacts with friends to having a very frequent number of contacts. Technically speaking, the possible disturbing influences of the variable, "the frequency of contacts with friends," are controlled. In this analysis the dependent variables are the same as above.

Table II (upper right portion) shows that there is some "interaction effect" for friends. The path coefficients increased from youngsters having low contacts with friends (0.39) to those having frequent contacts with friends $(0.52)$. The more often boys and girls have contacts with their friends, the stronger the impact of the deviancy of these friends.

The impact of the deviancy of the parents is much weaker than that of friends and diminishes when their children have frequent contacts with their friends (see upper left portion of Table II). But this finding is still in accordance with the DA theory.

Table II. Specification of Social Influences on the Development of Positive Definitions and on the Frequency of Communication About Techniques, Dependent on the Frequency of Contact with Friends ${ }^{a}$

\begin{tabular}{|c|c|c|c|c|c|c|}
\hline \multirow{2}{*}{$\begin{array}{l}\text { Frequency of } \\
\text { contacts with } \\
\text { friends }\end{array}$} & \multicolumn{3}{|c|}{ Deviancy of parents } & \multicolumn{3}{|c|}{ Deviancy of friends } \\
\hline & Pearson & Path & $R^{2}$ & Pearson & Path & $R^{2}$ \\
\hline \multicolumn{7}{|c|}{ Positive definitions of deviant behavior } \\
\hline Low $(N=138)$ & 0.29 & 0.15 & $2.0 \%$ & 0.45 & 0.39 & $19.9 \%$ \\
\hline Few $(N=209)$ & 0.24 & 0.13 & $1.5 \%$ & 0.50 & 0.47 & $24.6 \%$ \\
\hline Mean $(N=448)$ & 0.23 & 0.17 & $2.8 \%$ & 0.52 & 0.50 & $27.2 \%$ \\
\hline Often $(N=107)$ & 0.28 & 0.19 & $3.6 \%$ & 0.50 & 0.47 & $25.5 \%$ \\
\hline Frequent $(N=126)$ & 0.15 & - & - & 0.52 & 0.52 & $26.6 \%$ \\
\hline \multicolumn{7}{|c|}{ Frequency of communication about techniques } \\
\hline Low $(N=138)$ & 0.08 & - & - & 0.33 & 0.33 & $11.0 \%$ \\
\hline Few $(N=209)$ & 0.28 & 0.18 & $3.2 \%$ & 0.42 & 0.38 & $17.9 \%$ \\
\hline Mean $(N=448)$ & 0.13 & - & - & 0.47 & 0.47 & $22.2 \%$ \\
\hline Often $(N=107)$ & 0.01 & - & - & 0.46 & 0.46 & $21.5 \%$ \\
\hline Frequent $(N=126)$ & 0.06 & - & - & 0.58 & 0.58 & $33.6 \%$ \\
\hline
\end{tabular}

aSource: Bruinsma (1985, p. 159). 
The same conclusion can be drawn for the explanation of the other dependent variable, "frequency of communication about techniques." In the lower right portion of Table II, a strong interaction effect for friends can be observed. This means that the more frequently youngsters have contacts with their friends, the stronger the impact of the deviancy of those friends on the frequency of communication (increasing from +0.33 to +0.58 ).

However independent of how often boys and girls have contacts with their friends, the deviancy of their friends is responsible for almost the total amount of the explained variance of the frequency of communication. The impact of the deviancy of the parents can be neglected, because it is too weak to interpret. Only in the case that the respondents have hardly any contact with their friends can some impact of the deviancy of their parents be observed, but this effect is too weak to be of theoretical importance.

The special analyses thus far show the following:

(1) The basic idea of the differential association theory can be corroborated, because it is the deviancy of others that exercises the strongest influence on the development of positive definitions and on the frequency of communication about relevant techniques.

(2) The impact of the deviancy of others is stronger the more frequently one has contact with deviant others. This fact is also in correspondence with the differential association theory.

(3) The research findings of this special analysis, however, cannot be compared with the results of other etiological studies. There exists, to my knowledge, no empirical research on this subject. The majority of studies in which the impact of friends or parents is investigated concerns only the direct impact of these contacts on the crime rates of youngsters. Other issues such as the impact on the development of positive definitions about deviant behavior or about the frequency of communication about techniques are not examined.

\section{EXTENSION 3: A SPECIFICATION OF INFLUENCE OF THE DEVIANCY OF OTHERS ON THE NORMS}

Finally, we consider the impact of deviancy of parents and of the deviancy of friends on the learning of norms regulating deviancy. For this topic some information about a rival theory of differential association theory, namely, the social control theory of Travis Hirschi (1969), is necessary.

In social control theory it is stated that young people will not become engaged in deviancy when they have strong bonds to society. These bonds are (a) the degree of attachment to their parents (a "warm nest," so to speak), which implies that one is more sensitive to the opinion of others if 
one has a close relation with them; (The concept of attachment can be seen as similar to identification, although there are minor differences of interpretation on the theoretical level. On the empirical level these differences can, in my opinion, be ignored.) (b) the degree of commitment to society (because they are anxious about losing something, material or emotional); (c) the degree of involvement, which means that when someone is too busy with conventional activities, he/she will have no time left for criminal acts; and (d) the existence of beliefs which disapprove deviant behavior, which means that adolescents accept the rules of society.

An important distinction between the two criminological theories can be seen with respect to their different views about the impact of attachment to the parents on the criminal behavior of young people. Social control theory states that, independent of the deviancy of the parents, the stronger the attachment to parents, the less likely that adolescents will be involved in crime. The DA theory, however, states that the stronger the attachment (or the degree of identification) with deviant parents, the more likely that adolescents will be involved in crime, and the stronger the attachment to conforming parents, the less likely that adolescents will be involved in crime.

A second topic of the debate between the two theories concerns the impact of deviant friends. In social control theory it is assumed that the impact of the deviancy of friends is strongest when adolescents have no or weak attachment to their friends. In the DA theory a rival proposition can be formulated: The stronger will be the impact of the deviancy of friends on the norms of adolescents regulating deviancy the more they are attached to the friends. To test these propositions, the respondents were divided into five groups depending on their scores on the variable, "identification with their friends or their parents." In this way the possible disturbance of the attachment of parents or friends is controlled. The dependent variable in Table III is the intensity of norms regulating deviancy. Independent variables are the deviancy of parents and the deviancy of friends and the frequency of contacts with both of them. For the test of the propositions, only the upper left and the lower right portions of Table III are of interest.

In the upper left portion it can be observed that the impact of the deviancy of the parents is stronger when the adolescents identify themselves more strongly with their parents. However, the evidence is not very convincing. There is a moderate interaction effect, but the finding is in accordance with the DA theory.

A second conclusion is that the impact of the deviancy of the friends is stronger than the impact of the deviancy of the parents, independent of the degree of identification with the parents and with the friends. In accordance 
Table III. Specification of the Impact of the Deviancy of Parents and Friends on the Intensity of Norms Regulating Deviancy, Dependent on the Degree of Identification with Parents or with Friends"

\begin{tabular}{|c|c|c|c|c|c|c|}
\hline \multirow{3}{*}{$\begin{array}{l}\text { Identification } \\
\text { with parents }\end{array}$} & \multicolumn{6}{|c|}{ Intensity of norms regulating deviancy } \\
\hline & \multicolumn{3}{|c|}{ Deviancy of parents } & \multicolumn{3}{|c|}{ Deviancy of friends } \\
\hline & Pearson & Path & $R^{2}$ & Pearson & Path & $R^{2}$ \\
\hline Weak $(N=129)$ & 0.04 & - & - & 0.44 & 0.45 & $19.5 \%$ \\
\hline Little $(N=251)$ & 0.05 & - & - & 0.38 & 0.38 & $14.4 \%$ \\
\hline $\operatorname{Mean}(N=210)$ & 0.25 & 0.19 & $3.7 \%$ & 0.36 & 0.33 & $13.0 \%$ \\
\hline Much $(N=316)$ & 0.28 & 0,20 & $3.8 \%$ & 0.45 & 0.41 & $20.2 \%$ \\
\hline Strong $(N=140)$ & 0.24 & 0.10 & $1.4 \%$ & 0.43 & 0.40 & $18.7 \%$ \\
\hline \multicolumn{7}{|c|}{$\begin{array}{l}\text { Identification with } \\
\text { friends }\end{array}$} \\
\hline Weak $(N=166)$ & 0.21 & 0.15 & $2.0 \%$ & 0.33 & 0.30 & $11.0 \%$ \\
\hline Little $(N=221)$ & 0.15 & 0.10 & $1.0 \%$ & 0.36 & 0.35 & $13.1 \%$ \\
\hline Mean $(N=286)$ & 0.14 & $\longrightarrow$ & - & 0.44 & 0.43 & $19.2 \%$ \\
\hline Much $(N=203)$ & 0.21 & 0.11 & $1.1 \%$ & 0.54 & 0.52 & $29.3 \%$ \\
\hline Strong $(N=164)$ & 0.18 & - & - & 0.53 & 0.52 & $28.4 \%$ \\
\hline
\end{tabular}

"Source: Bruinsma (1985, p. 202).

with the differential association theory is the finding that the stronger the identification with friends, the stronger is the impact of the deviancy of friends on the norms regulating deviancy. The path coefficients increase from 0.30 for those with a weak identification with their friends to 0.52 for those having a strong relationship with their friends.

\section{CONCLUSIONS}

Hirschi and Gottfredson (1980) stated the following about the DA theory: "Since the theory of differential association neither predicts nor explains criminal behavior, its continued dominance cannot be explained on grounds of scientific adequacy. An alternative hypothesis is that differential association and its variants survive for the very reason that they are somehow protected from scientific research and are inimical to the development of healthy theoretical competition" (p. 9). Hopefully this study has demonstrated the inadequacy of their nullifying judgment about the DA theory. For this demonstration use is made not of immunizing strategies at which Hirschi and Gottfredson have hinted, but of clear theory testing empirical research open to any criticism. Although the theory of Sutherland has a less than bright empirical history, the tests demonstrate that we should not file it as 
a museum piece or label it as an abstract scientistic theory without any empirical foundation. Moreover, the interaction and communication processes in the sense of Sutherland are fundamental for the explanation of crime and delinquency.

The conclusion is that K.-D. Opp's version of the differential association theory is fairly well corroborated by the data. Only three of the postulated relationships are rejected. The theory explains $51 \%$ of the variance of criminal behavior, even considering that no "criminal" population is used for the test and only minor offenses have been measured. The test also shows that the impact of the frequency of contacts with deviant behavior patterns on the development of positive definitions and on the frequency of communication about relevant techniques is substantial and cannot be ignored by criminologists.

Furthermore, the special analyses show that several propositions are in favor of the theory. It is the deviancy of others that has the most substantial impact on the development of positive definitions, followed in decreasing order by the frequency of contacts. Also in favor of Sutherland's theory is the fact that an interaction effect is observed: the more youngsters have contact with their friends, the stronger the impact of the deviancy of those friends on the development of positive definitions or on the frequency of communication about techniques.

The tests also show that the more youngsters identify themselves with others, the stronger will be the impact of the DA theory by Opp and falsify some propositions of social control theory.

\section{APPENDIX}

Table AI. Pearson Correlations of the Concepts of the DA Theory, K.-D. Opp's Version (Means and Standard Deviations; $N=960)^{\circ}$

\begin{tabular}{lcccccccccccc}
\hline & IA & IB & II & III & IVA & IVB & V & VI & VII & VIII & IX & X \\
\hline IA & - & & & & & & & & & & & \\
IB & 0.22 & - & & & & & & & & & & \\
II & $0.01^{*}$ & $0.04^{*}$ & - & & & & & & & & & \\
III & 0.33 & 0.45 & $0.03^{*}$ & - & & & & & & & & \\
IVA & 0.82 & 0.19 & $-0.04^{*}$ & 0.27 & - & & & & & & & \\
IVB & 0.24 & 0.92 & $0.02^{*}$ & 0.44 & 0.20 & - & & & & & & \\
V & 0.25 & 0.41 & $0.07^{*}$ & 0.50 & 0.16 & 0.42 & - & & & & & \\
VI & 0.20 & 0.21 & $-0.02^{*}$ & 0.34 & 0.18 & 0.20 & 0.29 & - & & & & \\
VII & 0.27 & 0.38 & $0.00^{*}$ & 0.54 & 0.24 & 0.38 & 0.46 & 0.32 & - & & & \\
VIII & 0.24 & 0.42 & 0.12 & 0.48 & 0.17 & 0.42 & 0.63 & 0.26 & 0.47 & - & & \\
IX & 0.24 & 0.39 & $0.05^{*}$ & 0.49 & 0.16 & 0.39 & 0.50 & 0.28 & 0.50 & 0.65 & - & \\
X & 0.27 & 0.43 & $0.05^{*}$ & 0.47 & 0.20 & 0.42 & 0.56 & 0.27 & 0.57 & 0.64 & 0.56 & - \\
\multicolumn{1}{l}{ Mean } & -3.29 & 0.67 & 4.54 & 22.63 & -7.35 & -0.10 & 12.29 & 10.30 & 5.12 & 9.97 & 8.04 & 15.10 \\
SD & 4.14 & 5.84 & 1.56 & 6.22 & 8.53 & 12.67 & 2.21 & 1.92 & 1.88 & 4.54 & 2.35 & 3.26
\end{tabular}


Table AI. Continued

$\begin{array}{ll}\text { IA } & \text { = Frequency of contacts with deviant parents } \\ \text { IB } & =\text { Frequency of contacts with deviant friends } \\ \text { II } & =\text { Priority of contacts with friends } \\ \text { III } & =\text { Positive definitions of deviant behavior } \\ \text { IVA } & =\text { The degree of identification with deviant parents } \\ \text { IVB } & =\text { The degree of identification with deviant friends } \\ \text { V } & =\text { Frequency of communication about relevant techniques } \\ \text { VI } & =\text { The intensity of needs } \\ \text { VII } & =\text { The intensity of norms regulating deviancy } \\ \text { VIII } & =\text { Effectivity of relevant techniques } \\ \text { IX } & =\text { Opportunities of deviant behavior } \\ \text { X } & =\text { Frequency of deviant behavior }\end{array}$

*Not significant $(<0.10)$.

"Source: Bruinsma (1985, p. 261).

\section{REFERENCES}

Agnew, R. (1985). Social control theory and delinquency: A longitudinal test. Criminology 23: $47-61$.

Bruinsma, G. J. N. (1981). De controletheorie van Travis Hirschi: toetsing van een causaal model. In Gunther Moor, L. G. H. (ed.), Grenzen van de jeugd, Ars Aequi Libri, Utrecht, pp. $57-77$.

Bruinsma, G. J. N. (1983). De controletheorie voor het grote en het kleine verschil. Tijdschrift Criminol. 25: $96-104$.

Bruinsma, G. J. N. (1984). De methode van zelfrapportage van delicten. Tijdschrift Criminol. 26: 295-308.

Bruinsma, G. J. N. (1985). Criminaliteit als sociaal leerproces. Een toetsing van de differentiëleassociatietheorie in de versie van $K,-D$. Opp, Gouda Quint, Arnhem.

Bruinsma, G. J. N. (1988). Massale criminaliteit, jeugd en de overheid. Delikt Delinkwent. 18: 151-163.

Bruinsma, G. J. N. (1989). Scaling and reliability problems in self-reported property crimes. In Klein, M. W. (ed.), Cross-National Research in Self-Reported Crime and Delinquency, Kluwer, Boston/Dordrecht, pp. 131-151.

Bruinsma, G. J. N. (1990). Schoolklaseffecten en crimineel gedrag: een multilevel-analyse van contextuele invloeden. Tijdschrift Criminol. 32: 1-12.

Bruinsma, G. J. N., and Zwanenburg, M. A. (1980), Deviante Socialisatie. Verslag van een pilot-study, Criminologisch Instituut, Nijmegen.

Bruinsma, G. J. N., Jongman, R., and Junger-Tas, J. (eds). (1985). Maatschappelijke bindingen en criminaliteit, Boom, Meppel.

Burgess, R. L., and Akers, R. L. (1966). A differential association reinforcement theory of criminal behavior. Soc. Problems 14: 128-147.

Carmines, E. G., and Zeller, R. A. (1979), Reliability and Validity Assessment, Sage, Beverly Hills, Calif.

Cloward, R. A. (1959). Illegitimate means, anomie and deviant behavior. Am. Sociol. Rev. 24: 49-59.

Cloward, R. A., and Ohlin, L. E. (1960). Delinquency and Opportunity. A Theory of Delinquent Groups, Free Press, New York.

Cohen, A. K., Lindesmith, A. L., and Schuessler, K. (eds.) (1965). The Sutherland Papers, Indiana University Press, Bloomington.

Cressey, D. R. (1964). Delinquency, Crime and Differential Association, Martinus Nijhoff, The Hague. 
Cressey, D. R. (1969). Epidemiology and individual conduct. In Cressey, D. R., and Ward, D. A. (eds.), Delinquency, Crime and Social Process, Harper \& Row, New York, pp. 557577.

Cressey, D. R. (1972). Role theory, differential association and compulsive crimes. In Rose, A. M. (ed.), Human Behavior and Social Processes. An Interactionist Approach, Routledge \& Kegan Paul, London, pp. 443-467.

de Fleur, M. L., and Quinney, R. (1966). A reformulation of Sutherland's differential association theory and a strategy for empirical validation. J. Res. Crime Delinq. 3: 1-22.

Farrington, D. P., Ohlin, L. E., and Wilson, J. Q. (1986). Understanding and Controlling Crime, Toward a New Research Strategy, Springer, New York.

Fiselier, J. P. S., and Verschuren, P. J. M. (1988). De differentiële associatietheorie als verklaring van crimineel gedrag. Tijdschrift Criminol. 30: 203-222.

Gaylord, M. S., and Galliher, J. F. (1988). The Criminology of Edwin Sutherland, Transaction Books, New Brunswick.

Glaser, D. (1969). Criminality theories and behavioral images. In Cressey, D. R. and Ward, D. (eds.), Delinquency, Crime and Social Process, Harper \& Row, New York, pp. 515530 .

Glaser, D. (1978). Crime in our Changing Society, Holt, Rinehart \& Winston, New York.

Glueck, S. (1956). Theory and fact in criminology: A criticism of differential association. Br. J. Deling. 7: 92-98.

Hindelang, M. J., Hirschi, T., and Weis, J. G. (1981). Measuring Delinquency, Sage, Beverly Hills, Calif.

Hirschi, T. (1969). Causes of Delinquency, University of California Press, Berkeley.

Hirschi, T. (1986). On the comparability of rational choice and social control theories of crime. In Cornish, D. B., and Clarkle, R. V. (eds.), The Reasoning Criminal. Rational Choice Perspectives on Offending, Springer Verlag, New York/Berlin, pp. 105-118.

Hirschi, T., and Gottfredson, M., (eds.) (1980). Understanding Crime. Current Theory and Research, Sage, Beverly Hills, Calif.

Janowitz, M. (1975). Sociological theory and social control. Am. J. Saciol. 81: 82-108.

Jensen, G. F. (1972). Parents, peers and delinquent action: A test of the differential association perspective. Am. J. Sociol. 20:84-103.

Johnson, R. E. (1979). Juvenile Delinquency and Its Origins: An Integrated Theoretical Approach, Cambridge University Press, Cambridge.

Junger-Tas, J., and Block, R. L. (eds.) (1988). Juvenile Delinquency in the Netherlands, Kugler, Amstelveen.

Krohn, M. D., and Massey, J. L. (1980). Social control and delinquent behavior: An examination of the elements of the bond. Sociol. Q. $21: 529-543$.

Laub, J. H., and Sampson, R. J. (1991). The Sutherland-Glueck debate: On the sociology of criminological knowledge. Am. J. Sociol. 96: 1402-1440.

Lilly, J. R., Cullen, F. T., and Ball, R. A. (1989). Criminological Theory. Context and Consequences, Sage, Newbury Park.

Matsueda, R. L. (1982). Testing control theory and differential association: A causal modeling approach. Am. Sociol. Rev. 47: 489-504.

Matsueda, R. L. (1988). The current state of differential association theory. Crime Delinq. 34: $277-306$.

Matza, D., and Sykes, G. (1957). Techniques of neutralization: A theory of delinquency. Am. J. Sociol. 22: 664-670.

Opp, K-D. (1974). Abweichendes Verhalten und Gesellschaftsstruktur, Luchterhand, Neuwied.

Rankin, J. H., and Wells, L. E. (1990). The effect of parental attachments and direct controls on delinquency. J. Res. Crime Delinq. 27: 140-165.

Sampson, R. J., and Groves, W. B. (1989). Community structure and crime: Testing social disorganization theory. Am. J. Sociol. 94: 774-802.

Severy, L. J. (1973). Exposure to deviance committed by valued peer group and family members. J. Res. Crime Delinq. 10: 35-46.

Short, J. F., Jr. (1957). Differential association and delinquency. Soc. Problems 4: 233-239. 
Short, J. F., Jr. (1958). Differential association with delinquent friends and delinquent behavior. Pacific Sociol. Rev. 1: 20-25.

Short, J. F., Jr. (1960). Differential association as a hypothesis: Problems of empirical testing. Soc. Problems 8: 14-24.

Springer, W. (1973). Kriminalitätstheorien und ihre Realitätsgehalt, Ferdinand Enke, Stuttgart.

Stratton, J. R. (1967). Differential identification and attitudes toward the law. Soc. Forces 46 : 256-262.

Sutherland, E. H. (1924). Criminology, Lippincott, Chicago.

Sutherland, E. H. (1934, 1939, 1947). Principles of Criminology, Lippincott, Chicago.

Sutherland, E. H. (1956). Development of a theory. In Cohen, A. K., Lindesmith, A. L., and Schuessler, K. (eds.), The Sutherland Papers, Indiana University Press, Bloomington, pp. $13-59$.

Sutherland, E. H. (1973). On Analyzing Crime, University of Chicago Press, Chicago.

Voss, H. L. (1964). Differential association and reported delinquent behavior: A replication. Soc. Problems 12: 78-85.

Wiatrowski, M., and Anderson, K. (1987). The dimensionality of the social bond. J. Quant. Criminol. 3: 65-81.

Wolfgang, M. E., and Ferracuti, F. (1969). The Subculture of Violence, Tavistock, London. 